\title{
0 cargo público de livre provimento na organização da administração pública federal brasileira: uma introdução ao estudo da organização da direção pública na perspectiva de estudos organizacionais*
}

\author{
Leonor Moreira Câmara**
}

SumÁrio: 1. Introdução; 2 . O cargo público de livre provimento: algumas características da direção pública na administração pública federal brasileira; 3. Estrutura e agência como referências do cargo público de livre provimento; 4. Conclusão.

Summary: 1. Introduction; 2. The public position filled by appointment: a few characteristics of public management in the Brazilian public administration; 3. Structure and agency as references for the public position filled by appointment; 4. Conclusion.

Palavras-chave: administração pública; cargo público de livre provimento; organização.

KEY WORDS : public administration; public position filled by appointment; organization.

A organização da administração pública federal brasileira é raramente abordada na pesquisa no campo de estudos organizacionais (EOs). Privilegia-se a tomada de decisão, seguindo-se a tradição de pesquisa operacional de cunho funcionalista. Contudo, direção é mais complexa e inclui decisão. A direção na administração pública federal brasileira se dá exclusivamente por meio de cargos de livre provimento. Tal realidade permite entender a direção como ação eminentemente política, cristalizada na organização da administração pública. Este artigo possui caráter metodológico e demonstra que o cargo público de livre provimento possui centralidade na orga-

* Artigo recebido em dez. 2007 e aceito em out. 2008.

** Doutora em administração pela Escola de Administração de Empresas de São Paulo da Fundação Getulio Vargas (Eaesp/FGV). Socióloga, professora adjunta do Programa de Pós-Graduação em Administração (PPGA/Face) da Universidade de Brasília (UnB). Endereço: SQS 109, Bloco E, ap. 419 — Asa Sul — CEP 70372-050, Brasília, DF, Brasil. E-mail: leonor@unb.br. 
nização da administração pública federal brasileira. Identifica, ainda, práticas de operação e interações no exercício da direção pública.

Public position filled by appointment in the Brazilian federal administration: an introduction to the study of public management organization from the organizational studies perspective

The organization of the Brazilian federal public administration is seldom addressed by organizational studies (OS) research. The decision-making process is privileged, according to the tradition of functionalist operational research. However, managing is more complex than decision-making, which is included by it. Management level in Brazilian federal public administration is completely filled by appointment. This reality makes us understand management as an utterly political action, crystallized in the public administration organization. This article has a methodological perspective and demonstrates that public positions filled by appointment are central to the Brazilian federal public administration,. It also identifies practices and interactions of public management.

\section{Introdução}

Segundo dados oficiais, em setembro de 2007, 20.124 servidores civis da administração direta, das autarquias e fundações do Poder Executivo federal, ocupavam cargos de direção e assessoramento superiores, os chamados DAS ${ }^{1}$ (Brasil, 2007). Os referidos cargos têm por característica o fato de serem de livre provimento. Na organização da administração pública brasileira os cargos de direção são providos exclusivamente mediante indicação. Pressupõe-se que a efetividade da ação estatal está condicionada à capacidade e às práticas de direção de seus agentes. Este artigo evidencia a centralidade do cargo público de livre provimento no contexto da organização da administração pública federal brasileira e, portanto, enquanto objeto de pesquisa em estudos organizacionais (EOs). Trata-se de ação necessária no contexto mais amplo de estudos das práticas de direção na referida administração.

A especificidade do campo de EOs no que se refere à administração pública é ponto de partida, pois entende-se que a produção de conhecimento nesse campo não pode ser compreendida fora do contexto próprio do mesmo. Prioriza-se, aqui, primeiramente, a dicotomia política e administração como procedi-

\footnotetext{
${ }^{1}$ Quantitativo dos ocupantes de DAS, segundo o nível de função — Siape. Inclui os servidores civis da administração direta, autarquias e fundações do Poder Executivo. Posição: set. 2007. Fonte: Boletim Estatístico de Pessoal, v. 12, n. 138, Ministério do Planejamento, Orçamento e Gestão. Secretaria de Recursos Humanos, out. 2007.
} 
mento de organização do pensamento. Ainda que não se realize como pressuposto da experiência vivenciada no cotidiano da administração, entende-se que a reflexão sobre a dicotomia deva estar direcionada para seu significado como elemento estruturante do campo de EOs, e também para sua força simbólica.

Considerando-se que a distribuição de cargos públicos federais de livre provimento vincula-se ao sistema político brasileiro, ${ }^{2}$ mas considerando-se também que na organização da administração pública não existe outra categoria de cargo que se vincule formalmente à direção pública e que o exercício da direção pública é uma atribuição diretamente relacionada a habilidades e competências específicas que diretamente implicam práticas de relacionamento com grupos de interesses, de coordenação das ações, de gestão e, por fim, nas ações e resultados da administração pública, torna-se relevante na produção de conhecimento, a partir de EOs, considerar a centralidade do cargo público na organização da administração pública federal brasileira.

Como procedimento de análise discute-se a noção de cargo público e de cargo público de livre provimento, tal como se apresenta na organização da administração pública federal. Para tanto, se fez uma interpretação de alguns aspectos estruturais, especificamente da norma em associação com as origens dos pressupostos conceituais e teóricos da administração e também da gênese da administração pública, o que evidenciou a necessidade de resgatar a contribuição do direito administrativo. A partir das características estruturais percebidas nas suas dimensões histórica e política, entendidas como não desvinculadas da prática do poder estatal, evidencia-se a centralidade do cargo público de livre provimento na organização da administração pública brasileira, e a construção do significado de cargo público diverso do prescrito. Este artigo demonstra, a partir de suas características normativas estruturantes, a centralidade do cargo público de livre provimento na organização da administração pública federal e, em decorrência, reflete acerca de sua constituição enquanto categoria de análise para a produção de conhecimento a partir de EOs e da contribuição teórica capaz de orientá-la, desenvolvida por Pierre Bourdieu.

Situado no contexto de um projeto de pesquisa, este artigo é apenas um dos passos necessários para a análise da organização de direção na administração pública federal brasileira que, entende-se, deve considerar sua prática,

\footnotetext{
${ }^{2}$ Trabalhos realizados por Cardoso (1975), Lafer (2002), Draibe (1985), Martins (1985), Gouveia (1994), Schneider (1994), Nunes (1997), entre muitos outros oriundos do campo das ciências políticas, apresentam visões politizadas da burocracia estatal, ainda que sob orientações teóricas diversas, nas quais com maior ou menor ênfase o cargo público de livre provimento surge com centralidade no sistema político e nas relações da administração com grupos de interesses.
} 
sendo a norma uma de suas dimensões estruturantes. É também necessário para o estabelecimento de relações entre os aspectos teóricos e os aspectos metodológicos da investigação científica.

\section{A organização da administração pública a partir do campo de EOS}

Entre os trabalhos mais recentes que criticam a produção nacional de conhecimento científico em EOs destacam-se Rodrigues e Carrieri (2000), Hemais e Vergara (2000), Vergara (2001), Vergara e Pinto (2001), Hemais e Vergara (2001), Motta, Alcadipani e Bresler (2001), Fischer (2003), Misoczky (2004) e Vergara e Carvalho (2005). Ainda que baseados, em sua grande maioria, apenas na qualidade formal ${ }^{3}$ da produção científica, o quadro que surge é preocupante, pois, conforme os próprios autores, ainda que por caminhos diversos, a baixa capacidade de teorização dos autores nacionais associa-se à grande influência da produção de conhecimento originada em outros países.

A produção nacional recente em EOs, associada à administração pública, é objeto de preocupação de Misoczky (2004), que constata que a tônica dos trabalhos nacionais sobre administração pública recai na "adequação do ideário gerencialista para o campo das organizações públicas" (Misoczky, 2004:1) e que os artigos estudados têm como característica dominante abordagens positivistas e foco na implementação de preceitos gerencialistas já superados e criticados nos países de origem. Esta realidade leva à produção de conhecimentos sobre a organização da administração pública de forte aspecto descritivo (pretensamente neutro) e descontextualizado das práticas. Especificamente, no que se refere à decisão pública, a referida produção favorece abordagens que isolam a decisão pública do regime político ou, ainda, vincula as decisões às racionalidades abstratas que se limitam aos aspectos descritivos da ação estatal, favorecendo abordagens que "naturalizam" a organização da administração pública.

Entende-se que a produção de conhecimentos científicos sobre a organização da administração pública brasileira que seja capaz de teorização deve necessariamente expressar conteúdos éticos. Para tanto, entende-se que questões afetas à estruturação do campo de EOs, entendidas como não isoladas da ação, devem ser enfrentadas.

\footnotetext{
${ }^{3}$ Segundo Demo (1992), um trabalho científico pode ser avaliado por sua qualidade formal e por sua qualidade política. A qualidade formal diz respeito ao domínio das habilidades técnicas, dos meios. Já a qualidade política coloca-se pela sua pertinência no conjunto dos saberes produzidos por determinada ciência, isto é, questão dos fins.
} 
Destacam-se aqui a forte influência da produção científica em EOs originada em contexto cultural diverso do nacional e a baixa capacidade de teorização, constatadas pelos autores que fizeram a crítica da produção nacional em EOs, como um problema que põe em questão a própria possibilidade de teorização no campo. É necessária a reflexão sobre o que é elemento-chave na estruturação do campo de EOs: a dicotomia política/administração.

Adota-se neste artigo a perspectiva de campo científico desenvolvida por Pierre Bourdieu (2004), com ênfase naquilo que faz a especificidade do campo científico, ou seja, a concordância entre concorrentes do "contrato tácito, inseparavelmente político e cognitivo, que funda e rege o trabalho de objetivação" (Bourdieu, 2004:33).

\section{0 recurso da dicotomia entre a ideologia e o método}

Destacam-se aqui três visões da dicotomia política/administração. As duas primeiras ideológicas: Uruguai (2002), por referir-se à administração pública brasileira e ao direito administrativo em sua gênese; e Wilson (1966), por referir-se à gênese do campo de conhecimento. Ambos os autores, personagens da política, estão coadunados com as discussões de Bodin, no período de nascimento do Estado moderno. E a terceira, de Weber (2000b, 1979, 1993), como recurso da ciência para produção de conhecimento.

O visconde do Uruguai, um dos principais articuladores da construção do Estado brasileiro, inspirado no nascente direito administrativo francês, expressou na obra Ensaio sobre direito administrativo, publicada em 1861, um entendimento a respeito da organização da administração pública, pautado sobretudo pela centralização do poder decisório e do controle sobre a atuação da administração (Uruguai, 2002:440).

A ideia de centralização administrativa associada à organização científica é a solução apontada por Uruguai para evitar-se o uso da administração para fins pessoais, como também para a própria existência do Império. A ideia de neutralidade da ciência da administração foi amplamente colocada por Uruguai, que em seu nome justificou a separação da política do que é administração, e o uso do cargo (emprego público como denominava) como ferramenta de negociação entre a administração central e regionais. ${ }^{4}$ Esse en-

\footnotetext{
${ }^{4}$ Lessa (1999) constata na Primeira República a permanência do arranjo organizacional/político focado no cargo público implementado no Império. Souza (2006) faz constatação muito próxi-
} 
tendimento coaduna-se com o contexto de sua atuação política e biografia de perfil conservador.

A visão da política como algo que interfere negativamente na administração ou, em outros termos, a visão de que a técnica seja neutra e que a ação deva pautar-se exclusivamente pela eficiência e eficácia, é encontrada em Woodrow Wilson (1966), cujo trabalho O estudo da administração pública (1887) é considerado um marco nos estudos sobre a administração pública, ao sugerir, especificamente, a separação "na prática" entre "política" e "administração" e o uso de regras de gerenciamento desenvolvidas na iniciativa privada, considerando-se a busca pela eficiência. Ideias posteriormente desenvolvidas por Goodnow (1900), White (1927), Willoughby (1927) e Dimock (1936).

Tal qual em Uruguai (2002), as justificativas de Wilson (1966) também devem ser entendidas num contexto mais amplo de construção de um discurso político. Rosenbloom (1993), referindo-se à administração pública norte-americana, aponta que a ideia de despolitização do serviço público associada a questões de ordem política assim como à decisão sobre determinada forma de gestão, vincula-se às questões mais amplas de constituição da hegemonia política. Para o autor, a ideia de eficiência propalada pelo gerencialismo reforça o que politicamente já está determinado e tem como resultado, entre outros, a concentração do poder no Executivo.

Souza (2006:35), ao associar o cargo público à configuração do sistema político brasileiro, aponta que "pouco tem sido feito a respeito de uma área importante onde as duas se encontram, e onde as forças regionais exercem grande poder: a política de nomeação de altos diretores no aparelho administrativo no Brasil". É justamente a inscrição na organização da administração pública do encontro entre os termos política e administração onde está situado o objeto da pesquisa da qual decorre este artigo.

Diferentemente da perspectiva ideológica que nega a política na administração pública em termos dicotômicos, como se pode observar em Uruguai (2002) e Wilson (1966), Weber (1993) vê em ambos os termos complementaridade, dinâmica e conflito, mais precisamente, uma "inseparável complementaridade" entre políticos e burocratas no mundo moderno. Ou seja, a

ma, para o período pós-1930. Embora não associe o arranjo a Uruguai, a autora constata que nas passagens do Império para a República e da Primeira República para o período seguinte o arranjo administrativo/político que relaciona o cargo público da união às lideranças regionais permaneceu, sem contudo deixar de ser transformado na perspectiva do que se denomina "modernização conservadora". 
administração e a política apresentam-se distintamente apenas como recurso metodológico, inserido na construção das características ideais típicas da dominação legal, expressão da racionalidade burocrática em oposição às paixões e interesses da política, não se conformando, ambos os termos, a distinções analíticas excludentes.

Da construção ideal típica do autor emerge seu entendimento de cargo público e o significado do mesmo no contexto mais amplo do Estado moderno, especificamente por meio da atividade pública organizada e exercida segundo critérios racionais, técnicos e legais. Weber associa a técnica da administração à base legal para compor o tipo ideal de dominação racional/legal. A associação entre as racionalidades legais e a técnica é possível porque ambas expressam os "mesmos pressupostos, valores, problemas e métodos", segundo destacam Prats e Catalá (1996:30).

As características selecionadas para composição do tipo ideal da dominação burocrática são todas decorrentes do reconhecimento da centralidade do cargo para o exercício da dominação por meio do quadro administrativo, no contexto de uma relação de trabalho com o poder estatal ${ }^{5}$ portadora de ethos próprio.

Tem-se, em relação à ideia de cargo, as seguintes características ampliadas (Weber, 1991:145): obrigações objetivas; despersonalizado; define-se pelas tarefas a serem desempenhadas; nomeação numa hierarquia rigorosa de cargos (rede escalar); competências funcionais fixas; cargo como profissão principal; existência de carreira; desempenho atribuído ao cargo e à ideia de um ethos próprio. Quanto ao seu ocupante: vínculo formal com a administração; qualificação certificada e remunerada com salários fixos e em dinheiro; recebimento de pensões; impossibilidade de apropriação dos cargos; submissão à disciplina e ao controle.

O modo como o cargo é constituído, no contexto da dominação burocrática, tal como Weber (2000a) a define, é garantia de obediência do quadro administrativo e permanência do modo de organização burocrático. Por outro lado, da expressão objetivada da dominação racional legal, conforme interpretado por Weber, o cargo público, na perspectiva de sua regulação, criação e distribuição, apresenta-se imbricado não apenas à organização da administra-

\footnotetext{
${ }^{5}$ Viana (1945), em documento institucional de apresentação das atividades do Dasp, destaca que as ideias de produtividade, racionalização e de Departamento de Administração Geral originadas na tradição anglo-saxônica estão na origem do Dasp e da instituição do sistema de carreira.
} 
ção pública, mas também ao poder político, pois seu exercício implica prerrogativas da autoridade estatal e expressa a forma como ela é distribuída.

A dicotomia composta pelos termos política e administração, como toda dicotomia, é um método de classificação de noções que busca a eficiência mediante a redução e o uso da técnica. Importa, pois, superar a retórica ideológica e discutir sua força reificadora e estruturante sobre o campo de EOs e sobre sua produção científica. Para tanto, há que se considerar, em relação ao seu uso (e ao campo ao qual se refere), sua dinâmica e poder de estruturar relações e conhecimentos, mais explicitamente, aquilo que nega e aquilo que reforça, e as possíveis concepções de administração.

\section{O cargo público de livre provimento: algumas características da direção pública na administração pública federal brasileira}

Discute-se importante marco da história de campo de EOs no Brasil; a "superação do direito administrativo" por abordagens gerencialistas, e a necessária construção da interdisciplinariedade com o referido campo do direito, no contexto do debate atual, que busca equacionar o denominado "problema da ação" nas ciências sociais.

Nos anos 1930, à administração científica incorporam-se as contribuições de Fayol (1973) e de Gulick (1973) com foco na organização estruturada e coordenada segundo objetivos econômicos e de eficiência. Fayol recomenda ao alto comando do serviço público, com base na teoria administrativa: definição de papel (planejamento, controle, assessoramento, informação, coordenação, organização e comando); meios de operação; estrutura e organização. Em Gulick, a informação e o controle contábil-financeiro recebem maior ênfase, embora o autor também prescreva planejamento, organização, coordenação, direção e assessoramento. Os preceitos da administração científica, contudo, permanecem.

A separação entre política e administração, como pressuposto da organização da administração pública federal, ganha reforço com a abordagem de Willoughby em Princípios de administração pública (1929). A referida teoria, elaborada no contexto de uma discussão mais ampla sobre a divisão de poderes do Estado, tem como pressuposto a separação entre política e administração e tem na eficiência operacional a finalidade da administração. Segundo Wahrlich (1983), Willoughby foi uma das principais influências das reformas promovidas por Getúlio Vargas após 1934. A referida teoria compõe as raí- 
zes doutrinárias do Departamento Administrativo do Serviço Público (Dasp) (Wahrlich, 1983:281).

A adoção da "teoria dos departamentos de administração geral" é evidenciada amplamente por Wahrlich (1983), assim como o papel desempenhado pelo Dasp na promoção de seus princípios associados aos desenvolvidos, principalmente, pelos trabalhos de Taylor (1963), Fayol (1973) e Gulick (1973). Evidência empírica é a própria concretização do modelo de organização.

Contudo, dois anos antes da criação do Dasp, a Lei do Reajustamento (Lei oㅡ 284, de outubro de 1936) criou carreiras segundo critérios de inspiração taylorista, ou seja, com foco no cargo organizado em classes (gradação) a partir das exigências de responsabilidade e dificuldade decorrentes da divisão do trabalho, diferentemente dos preceitos da administração científica que situa o cargo no contexto de uma carreira.

Há que se considerar ainda que, segundo Luiz Simões Lopes (Brasil, 1940), presidente do Dasp, do início ao fim do Estado Novo, justificava-se tal interpretação como decorrência da prevalência da visão de função pública sobre a visão do contrato de trabalho. Segundo Lopes, se nesta última o funcionário é um preposto da administração vinculado ao cargo que ocupa, na visão de função pública ele é membro de um corpo, ocupante de um cargo, mas qualificado para ocupar outros cargos (Brasil, 1940). Essa interpretação foi incorporada em 1939 no primeiro Estatuto dos Funcionários Civis da União e está em vigor até hoje conforme se pode observar na Lei Estatutária no 8.112 , de 1990 .

Entende-se que a "superação" do direito administrativo pelo enfoque gerencial de origem norte-americana, tal como coloca Wharlick (1979), não é medida de desenvolvimento de EOs, como colocado, mas sim de seu empobrecimento, ${ }^{6}$ pois escapam ao enfoque eminentemente gerencial da organização da burocracia as dimensões histórica e social e os valores associados à sua constituição. Não se trata da adoção de categorias jurídicas como dado, mas sim, reconhecer sua dimensão estruturante, em se tratando da administração pública. Acrescente-se que o enfoque reproduz uma concepção de norma jurídica reducionista e empobrecedora da dinâmica social ${ }^{7}$ e confunde ordem

\footnotetext{
${ }^{6}$ Spink (1999) aponta o silêncio reinante no campo em relação ao que para ele é uma das principais, senão a principal, característica da administração pública brasileira: o fato de ser regulada pelo do direito público.

${ }^{7}$ A título de exemplo, pois foge ao objeto deste artigo, destaca-se a obra do visconde do Uruguai, Ensaio de direito administrativo, de 1862, como constituinte da administração pública brasileira. Acrescente-se ainda que o direito administrativo não exclui a gestão, nem a doutrina é contraditória
} 
jurídica com dominação legal, ${ }^{8}$ ou ainda norma jurídica com ação, fato que tende a fortalecer a visão gerencialista.

Tem-se que o foco no cargo como conjunto de atribuições e responsabilidades, típico do taylorismo, foi sobrepujado pela ideia de cargo por categorias profissionais, tradição que foca as qualidades do indivíduo que ocupa o cargo e não o cargo a priori (Wahrlich, 1983:122). Em decorrência, constitui-se a associação das noções de cargo e servidor como autorreferentes, consubstanciando-se numa única noção: cargo é o conjunto de atribuições e responsabilidades cometidas a um funcionário e este é a pessoa legalmente investida em cargo público (Lei no 8.112/90).

Formalmente, quanto ao tipo de provimento, os cargos do serviço civil da União são classificados em: efetivo ou em comissão, com o primeiro dependente de habilitação em concurso e o segundo não. Os cargos da administração direta classificados como de provimento em comissão constituem dois grupos: o grupo denominado direção e assessoramento superiores, sendo este subdividido em duas categorias, direção e assessoramento superiores e assessoramento superior; e o grupo denominado cargos de natureza especial. ${ }^{9}$ O primeiro grupo compreende "as atividades de fiança, abrangendo planejamento, supervisão, coordenação, orientação e controle, no mais alto nível da hierarquia dos órgãos da administração federal direta". ${ }^{10}$

Quanto ao cargo público de livre provimento, destaca-se que a classificação "livre provimento" aplica-se em decorrência de não haver formalidades quanto à seleção de seu ocupante, ou seja, livre provimento é atributo do cargo público e não da pessoa que nomeia. A motivação para escolha do ocupante

com os pressupostos de Willoughby (1919). Na obra de Uruguai pode-se observar o funcionário público especializado e profissional e o não especializado; a eficiência da ação estatal; eficácia da gestão; a imparcialidade; a previsibilidade; a responsabilidade; a organização funcional da administração entre outras questões estruturantes da organização da ação da administração pública. A dicotomia ordenadora entre os termos política e administração também está presente. Se ambos visavam fortalecer o Poder Executivo mediante a centralização político-administrativa, os motivos divergiam. Em Uruguai tratava-se de responder à experiência republicana promovida pela regência de Feijó em nome do que denomina razão nacional e da liberdade. Willoughby focalizou a gestão, mas sua aplicação pelo Dasp também se deu num momento de centralização político-administrativa.

${ }^{8} \mathrm{Na}$ obra de Weber, dominação legal só existe quando praticada (o mando e a obediência) em associação à crença na legitimidade da ordem jurídica. A esse respeito ver Bendix (1986).

${ }^{9}$ Lei no $8.112 / 90$

${ }^{10}$ Lei no $5.645 / 70$, Decreto no $77.336 / 76$. 
do cargo, futuro servidor, independentemente se originado ou não de carreira no serviço público, depende exclusivamente de quem nomeia.

Cabe destacar que, independentemente do critério utilizado para indicação do ocupante do cargo, a posse cria o servidor, caso este já não o seja. Existem requisitos formais quanto à sua regulação decorrente do regime estatutário ao qual se submete devido à sua inserção na estrutura hierárquica ${ }^{11}$ da administração. Também existem requisitos formais quanto às suas atribuições funcionais associadas ao lugar que ocupa na hierarquia, bem como quanto às atribuições que o ato de nomeação definir. Requisitos que têm referência, quanto ao conteúdo e denominação, no ideal de organização expresso na gradação da hierarquia escalar tal como Fayol e Gullick a concebem.

Essa realidade, que combina técnicas de organização da administração científica com a concepção de órgão, de corpo funcional, vigente desde 1939, qualifica a centralidade do cargo público na administração pública federal brasileira. O significado e a força dessa concepção de cargo público são encontrados nos próprios fundamentos da organização da administração pública federal.

É privilegiada, neste artigo, a função de direção, viabilizada mediante acesso ao cargo público classificado como de livre provimento. Não existe outra forma de exercê-la na administração pública federal brasileira. Inicialmente, esse fato já implica expectativas de desempenho do cargo associadas aos interesses políticos de quem tem o poder de nomear. Por esse motivo exige-se lealdade pessoal do nomeado, e seu vínculo é precário. Acrescente-se que o provimento em comissão implica também a não associação do cargo a nenhuma especialidade de ordem técnica. Para isso existem os cargos de pro-

\footnotetext{
${ }^{11}$ São classificados separadamente e hierarquicamente em seis níveis denominados DAS 101.6 a DAS 101.1 e a cada nível atribui-se as seguintes funções. Direção — DAS 101.6: secretário de órgãos finalísticos; dirigentes de autarquias e fundações; subsecretários de órgãos da PR; DAS 101.5: chefe de gabinete de ministro de Estado; diretor de departamento; secretário de controle interno; subsecretário de planejamento, orçamento e administração; DAS 101.4: coordenadorgeral; chefe de gabinete de autarquias e fundações; chefe de assessoria de gabinete de ministro de Estado; DAS 101.3: coordenador; DAS 101.2: chefe de divisão; DAS 101.1: chefe de seção; assistência intermediária. Diferentemente do DAS de direção, o DAS de assessoramento compõe o gabinete ministerial. Sua posição e função possibilitam acesso privilegiado a conhecimentos, à informação, e atuam sobre a hierarquia no sentido de facilitar, controlar, influenciar e implementar decisões. Diferentemente dos cargos em comissão de direção, os de assessoria, formalmente, não tomam decisões formais, mas atuam em nome e sob a direção da autoridade de gabinete. São classificados da mesma forma que os cargos de direção, mas têm como função a assessoria. Assessoramento - DAS 102.6: assessor especial; DAS 102.5: assessor especial de ministro de Estado; DAS 102.4: assessor; DAS 102.3: assessor técnico; DAS: 102.2 assistente; DAS 102.1: assistente técnico.
} 
vimento efetivo, e aí vale a regra do concurso público. Outra característica do cargo público de livre provimento é seu poder hierárquico sobre os demais de provimento efetivo e poder de Estado.

Esse fato estruturante é de suma importância numa discussão acerca da centralidade do cargo público na administração, pois a prestação de serviços pelo Estado dá-se mediante ação ordenada e coordenada na forma de políticas públicas, entendidas aqui de forma ampla, como processo político de escolha de prioridades de governo que incorpora os meios e as ações, ambos enquanto instrumentos e espaços de atuação do agir e da manifestação de poder, não sendo, portanto, abstratos nem isolados um do outro (Subirats, 1992; Ozlack, 1975).

No direito administrativo, a característica estatal do cargo público evidencia-se, pois a atividade administrativa é meio pelo qual se realiza uma função pública, a função administrativa. ${ }^{12}$ Tal função se refere à atividade exercida segundo procedimentos, modos de operação, meios materiais, organizacionais e regimes jurídicos específicos e que têm como pressupostos a indisponibilidade dos interesses públicos e a supremacia da lei (Mello, 2002; Modesto, 1995). Para esta concepção de administração pública republicana, por princípio, além dos resultados (o que e para quem), importa também como as atividades são exercidas.

Assim, atribuições ou atividade administrativa referem-se a parcelas de poder estatal exercido enquanto dever e de modo regulado por princípios, pela lei, pela hierarquia, que é pautada em relações de mando e controle, pelo controle externo etc. Nesse contexto, Mello (2002) entende explícita a relação do cargo público com o poder estatal, ao definir cargo público como "denominação dada à mais simples unidade de poderes e deveres estatais a serem expressos por um agente", ou seja, é inerente ao agente investido em cargo público, o denominado servidor, determinada dimensão do poder (dever) estatal.

No campo do direito administrativo, tem-se o contexto e também a própria definição de atividade administrativa da administração pública, que envolve tanto determinações quanto restrições para o agente. Por ser expressão do poder racional, seu exercício pressupõe limitações quanto às atribuições, competência técnica e quanto à sua eficácia. Ainda que se considere a discricionariedade, a noção de poder oriunda do direito administrativo refere-se ao poder regrado que foca não a ação em si, mas seu controle.

\footnotetext{
${ }^{12}$ Legislação e jurisdição também são consideradas funções públicas e, a depender do autor, governo também (Modesto, 1995).
} 
A compreensão da dimensão organizacional do cargo público de livre provimento como expressão da divisão do poder estatal, poder característico que regula as relações entre a administração e os administrados, não prescinde, entende-se, da norma racionalmente estabelecida como quadro de referência da ação. Contudo, tal como Weber o concebe, tal quadro de referência não exclui outros, também associados à práxis social, e que a ele remetidos tornam inteligível a experiência da ação organizada associada à direção pública.

No direito administrativo o poder é visto como estatal e organiza-se para a ação segundo uma estrutura funcional de distribuição de competências em organizações e cargos, de forma que falar em poder no âmbito da administração pública, da perspectiva do direito administrativo, é falar de poder estatal. Poder aplicado e distribuído sobre um arranjo fixo organizado verticalmente, numa escala de ordem na qual a distribuição de poder, incluído aí o controle sobre seu exercício, concentra-se no nível mais alto e, progressivamente, a partir dele, reduz-se em direção aos denominados escalões inferiores, gerando obrigação de subordinação progressiva à autoridade. Tem-se aqui, como expressão da racionalidade legal, uma concepção abstrata de poder, historicamente estruturado, como atributo da autoridade estatal, legítima e em cujo modelo de ordem se expressa uma relação de mando e obediência. Destaca-se também, como dimensão complementar e necessária ao exercício do poder estatal, sua dimensão simbólica observável, especificamente no que tange ao cargo público, como os atos de nomeação e a investidura (Bourdieu, 2003:146).

Há que se destacar que, embora decorra do cargo, o poder a este atribuído, por não ser capaz de ação por si só, redireciona o olhar para a agência, ou seja, o agente no uso de suas faculdades de coordenação e comando e situado no contexto de suas normatividades, vinculações e interações sociais. Ressalta-se aqui a importância dos meios, dos instrumentos, das práticas de gestão e de coordenação para o exercício da ação de dirigir, de modo que as práticas operacionais, em suas dimensões política, técnica e ética, sejam abordadas.

\section{Estrutura e agência como referências do cargo público de livre provimento}

Estrutura e ação são termos-chave em EOs. Segundo Reed (1999), o debate teórico recente em torno dos referidos termos tem sido no sentido de constituição de uma síntese entre ambos. 
As concepções de agência e estrutura, especialmente a motivação e natureza da ação individual e a constituição de estruturas e instituições coletivas, são pressupostos das ciências sociais.

Por pressupostos, entendo as suposições mais gerais que os sociólogos fazem quando se defrontam com a realidade. Cada teoria social e cada trabalho empírico tomam posições a priori que permitem que os observadores organizem nas categorias mais simples os dados dos sentidos que entram em suas mentes. E é só nessa base que são possíveis as manipulações mais conscientes que constituem o pensamento racional ou científico.

(Alexander, 1987:8)

Segundo Alexander (1987:23), o reconhecimento do esgotamento das tradições micro e macrossociológicas, surgidas e radicalizadas no bojo da crítica ao estrutural funcionalismo, levou, na década de 1980, à busca de uma síntese. Para o autor, a referida síntese tem como desafio o reconhecimento da "centralidade do significado coletivamente estruturado, ou cultural".

A abordagem institucionalista de vertente sociológica, abordagem originada na sociologia das organizações num contexto de crítica à tradicional oposição entre estrutura e ação (que tem grande força no campo de EOs), implica os termos estrutura e ação serem vistos como práticas culturais (Hall, 2003:207).

Contudo, segundo Hall (2003:80), a dimensão do conflito ainda recebe pouca atenção dos autores. Peci (2003) acrescenta que, embora tenha incorporado as dimensões cultural e simbólica inerentes à ação de organizar, estas são consideradas variáveis intervenientes. Destaca-se também a ênfase na estrutura como aspecto normativo. Fato que não favorece a compreensão da ação relacionada ao modo de organização nem à organização como ação de organizar.

Em trabalho que estuda as sínteses teóricas de Giddens e Bourdieu, especificamente no que se refere, no campo de EOs, à relação objetividade/subjetividade, Peci (2003) considera as possibilidades da aplicação dos referenciais teóricos desenvolvidos por Giddens e por Bourdieu em teoria organizacional, sobretudo por se tratar de trabalhos de síntese entre as perspectivas macro e micro, que têm rigidamente caracterizado o campo de EOs.

Contudo, Peci (2003:33) destaca que autores nacionais ${ }^{13}$ que fazem uso da contribuição de Bourdieu têm se restringido ao conceito de campo isola-

\footnotetext{
${ }^{13}$ Misoczky (2001); Carvalho e Lopes (2001); Leão (2001).
} 
damente, "o que impressiona, considerando que se perde o foco da síntese e abre espaço para sérios questionamentos da validade de tais pesquisas, uma vez que, para o autor, habitus e campo são dialeticamente relacionados".

Em decorrência, para Peci (2003), o potencial da síntese teórica realizada por Bourdieu não é explorado.

Misoczky (2003 e 2004) é a autora que mais tem publicado trabalhos ensaísticos acerca das possibilidades da contribuição da obra de Bourdieu para estudos organizacionais. Com base na concepção de pesquisa multiparadigmática, discute as interfaces da noção de campo de poder de Bourdieu e demais noções a ele relacionadas, como a noção de campo organizacional de DiMaggio e Powell (1991), e vê na obra de Bourdieu um potencial de rompimento com a tradição em estudos organizacionais.

Quanto à qualidade da aplicação da abordagem de Bourdieu, Misoczky (2003) destaca a problemática do uso de conceitos oriundos da obra de Bourdieu sem a necessária compreensão da complexidade de sua obra. Como procedimento paradigmático, cita os institucionalistas DiMaggio e Powell (1991), de grande influência na produção nacional em EOs, que reinterpretam a noção de campo de Bourdieu imprimindo-lhe certo esvaziamento. Essa realidade reforça a importância de trabalhos que procuram divulgar o método desenvolvido por Bourdieu como em Thiry-Cherques (2006).

Para aqueles que procuram compreender a aplicação da teoria de Bourdieu em EOs, há que se relativizar as observações de Peci (2003) e Misoczky (2002 e 2003), sobretudo pelas características do próprio campo já apontadas anteriormente. É de se supor que a incorporação da obra de Bourdieu enfrentará desafios, pois a incorporação num campo de produção de conhecimento de determinada contribuição teórica dá-se segundo lógicas a ele inerentes e implica considerações acerca do conhecimento tradicionalmente produzido. Bourdieu evidencia tal realidade a partir de seu trabalho sobre o campo científico (Bourdieu, 2004). É o que demonstram Catani, Catani e Pereira (2001) em estudo sobre as características da recepção da obra de Pierre Bourdieu, especialmente para o campo educacional brasileiro. ${ }^{14}$ Entende-se que uma sínte-

\footnotetext{
${ }^{14}$ Catani, Catani e Pereira (2001) associam modos de recepção às dinâmicas internas do campo, incluindo aí as características dos principais debates, a cultura intelectual e a estrutura do próprio campo. Da referida associação evidenciam uma lenta mas progressiva recepção do arcabouço teórico metodológico de Bourdieu, não sem antes passar e ainda conviver com outras formas de recepção, especificamente uma prática que apenas faz referências descoladas do contexto dos argumentos e outra que apropria-se de fragmentos da obra como reforço ao argumento, denominadas pelos autores como incidental e conceitual-tópica, respectivamente. O referido
} 
se teórica apropriada deva considerar a incorporação das dimensões cultural, social e interativa que caracterizam a agência, tal como encontrada na obra de Bourdieu. Dimensões pensadas a partir de "problemáticas que evidenciem a presença de uma estrutura subjacente ao social" (Thiry-Cherques, 2006:28).

Destacam-se aqui algumas características da abordagem de Pierre Bourdieu que, entende-se, justificam a adoção de sua produção intelectual em EOs: procura revelar os aspectos culturais que envolvem a ação; é operacionalizada por meio de um sistema conceitual fortemente ancorado em práticas culturais; sua abordagem, a partir da noção de habitus e campo, possibilita a investigação das interfaces entre as esferas da agência e da estrutura. E, também, pela articulação entre teoria e evidências empíricas proporcionada pelo método desenvolvido pelo autor, o que abre a possibilidade de teorização a partir de problemas empíricos, constituindo assim um pensamento não teleológico, nem apegado às ideias de funções e de sistemas típicas da abordagem estrutural-funcionalista, entre outras abordagens funcionalistas que têm prevalecido em EOs.

Segundo Pinto (2000), o habitus em Pierre Bourdieu deve ser entendido no contexto relacional entre práticas e estruturas objetivas tornadas passíveis de visualização a partir da noção de campo. Já a noção de campo deve ser entendida como procedimento metodológico que permite o uso controlado do raciocínio causal e que, por ser dotado de leis próprias, permite, num determinado microcosmo social, a explicitação da ordem de coexistência dos agentes sociais e da reprodução da ordem social (Pinto, 2000:71).

Os princípios de um campo são determinados concretamente pela existência de relações objetivas e circunstanciadas e pela dinâmica relacional entre os agentes que o compõem e que definem suas próprias leis. Ou seja, um campo, que é uma criação dos agentes que o compõem, não é uma construção abstrata, mas estruturada a partir de uma perspectiva relacional objetiva entre e sobre os agentes (Bourdieu, 2004:23).

É a distribuição do capital entre os agentes que determina a relevância do agente no contexto relacional e sua posição na estrutura do campo,

trabalho, cujo universo compreende o período de 1971 a 2000, revela uma dinâmica que tem três práticas distintas de apropriação: a) incidental, onde não existe relação entre a argumentação e a referência; b) apropriação conceitual tópica, em que se busca reforçar o argumento, mas não se faz uso de aspectos globais da obra do autor; e c) apropriação do modo de trabalho, onde se faz uso sistemático de conceitos e do modus operandi do autor. O resultado, em quantidade, se expressa respectivamente em $67 \%, 18 \%$ e $15 \%$ do universo pesquisado, e vincula-se, também respectivamente, às décadas de 1970, 1980 e 1990 (Catani, Catani e Pereira, 2001). 
ou seja, as possibilidades de ação do próprio agente. A importância da noção de capital no contexto mais amplo da teoria bourdiana decorre do fato de o capital ter múltiplas propriedades e de um campo, ao possuir regras próprias de funcionamento, poder favorecer uma ou outra propriedade do capital que, por serem decorrentes de valores estabelecidos e reconhecidos pelos próprios agentes, são simbólicas e determinam o lugar que o agente ocupa na estrutura, seu relacionamento com os demais agentes e a reprodução do campo.

A noção de campo pressupõe um pensamento relacional que busque um sentido de ordem. Bourdieu vê, na ordem, caracterizações simbólicas estruturadas a partir de relações que definem posições, regularidades e previsibilidades entre os agentes. Entende-se ordem como caracterização simbólica que exprime desigualdade, tanto das experiências vividas quanto entre o pensar e o ser, impondo o dever-ser da prescrição, ainda que não formalizada. Trata-se de uma relação de poder dinâmica e mediada pelo simbólico, em associação com a linguagem corporificada no discurso da ordem e que busca conservarse, renovando-se. A ordem é a corporificação da razão, da racionalidade e da intolerância perante outras possibilidades.

Estruturas existem na medida em que o agente as legitima, relacionando-se, e que a dinâmica ordem/desordem expressa visões de sociedade. Para Bourdieu (2003:128), trata-se de desvelar os princípios de construção da ordem social e os conteúdos e modos de percepção e práticas que fundamentam o sentido dado, compartilhadamente, pelos agentes sociais ao mundo social. Como a ordem social é ela mesma socialmente construída, o caminho inverso, ou seja, o consenso compartilhado, reforça a ordem social estabelecida, tendo-se o que Bourdieu denomina "círculo de reprodução da ordem social".

Contudo, a noção de habitus bourdiana não se interessa pelos comportamentos regulados (Pinto, 2000:38), ou seja, é pelo desajustamento que o habitus se torna manifesto e permite "saber o como e em que limites se verificam o ajustamento entre as estruturas objetivas e as estruturas interiorizadas, incorporadas pelo agente sob a forma de senso prático" (Pinto, 2000:39).

No contexto do arcabouço teórico-conceitual de Bourdieu, o cargo público de livre provimento é entendido como uma entre outras formas de expressão das estruturas objetivas da agência imbuída de poder estatal, especificamente no que diz respeito à direção pública, aqui representada pelo que, em tese, imprime legitimidade. Trata-se de procedimento fundamental para o delineamento de um campo. 


\section{Conclusão}

A construção do significado atribuído ao cargo público de livre provimento, a partir da interpretação da dimensão normativa da estrutura, evidenciou, à luz do referencial teórico existente, ambiguidades como uma característica da organização da administração pública no que se refere à direção. Contudo, entende-se que se deve ir além da constatação de ambiguidades perante determinadas abordagens teóricas, avançando no sentido da teorização a partir da prática, na busca de um sentido mais preciso acerca da organização da administração.

Com foco no exercício da direção pública e levando-se em conta as características acima elencadas, há que se considerar, tendo em vista a gênese e o desenvolvimento do modelo de ordem expresso na ação de organizar a administração pública, que a agência e a estrutura confundem-se, que não existe distinção entre esses termos, sendo a prática, aqui, elemento considerado inerente ao modo de organização.

Há que se considerar, também, que o exercício do poder estatal decorrente do cargo não deve ser entendido exclusivamente como atributo da hierarquia, nem como voluntarismo do agente, mas sim, tal como Bourdieu concebe a noção de poder, como efeito das relações estabelecidas entre quem pratica e quem sofre a ação. Daí a importância, para a teoria da ação desenvolvida pelo autor, do agente socialmente referenciado, portador de habitus, em interação com as estruturas objetivas, históricas, que se consubstanciam em espaços de poder, no âmbito do qual se constitui um campo.

Por fim, o foco a ser considerado, em se tratando da produção de conhecimento em EOs, deve recair sobre a agência a partir do cargo, ou seja, como o agente exerce a direção no universo da organização da administração pública, o que inclui interagir com uma pluralidade de interesses sociais e fazer uso de recursos materiais, instrumentais e simbólicos. Considera-se, aqui, o cargo público como expressão da dinâmica do modo de organização da administração pública, expressão de fração do poder estatal e portador de significados diversos, não abstrato portanto, mas, necessariamente, associado à agência. Essas dimensões possibilitam o olhar sobre a direção no amplo e complexo contexto da organização da administração pública federal brasileira e chama a atenção para a centralidade do exercício da direção pública na produção do saber em EOs. 


\section{Referências}

ALEXANDER, Jeffrey C. O novo movimento teórico. Revista Brasileira de Ciências Sociais, v. 2, n. 4, p. 5-28, 1987.

BENDIX, Reinhard. Construção nacional e cidadania: estudos de nossa ordem social em mudança. São Paulo: Edusp, 1996.

BERTERO, C. O.; KEINERT, T. M. A evolução da análise organizacional no Brasil. Revista de Administração de Empresas, v. 34, n. 3, p. 81-90, 1994.

; CALDAS, M. P.; WOOD JR., T. (Orgs.). A produção de conhecimento científico em administração no Brasil. Relatório de Pesquisa. São Paulo: FGV/Eaesp, 1999.

Paulo: Arlas, 2005. . Produção científica em administração no Brasil. 1. ed. São

BOURDIEU, Pierre. A profissão de sociólogo: preliminares epistemológicas. 2. ed. Petrópolis, RJ: Vozes, 1999.

. Os usos sociais da ciência. 6. ed. São Paulo: Unesp, 2004.

BRASIL. Presidência da República. Departamento Administrativo do Serviço Público. Estatuto dos funcionários: estudos e projetos. Rio de Janeiro: Imprensa Nacional, 1940. $418 \mathrm{p}$.

. Ministério do Planejamento, Orçamento e Gestão. Secretaria de Recursos Humanos. Boletim Estatístico de Pessoal, v. 1, n. 1, maio 1996. Brasília: MP, 2006. Descrição baseada no v. 12, n. 129, jan 2007.

. Ministério do Planejamento, Orçamento e Gestão. Secretaria de Recursos Humanos. Boletim Estatístico de Pessoal, v. 1, n. 1, maio 1996. Brasília: MP, 2007. Descrição baseada no v. 12, n. 138, out. 2007.

. Organização Institucional das Estruturas do Poder Executivo Federal. Atos legais e normativos, maio 2007. Disponível em: <www.planejamento.gov. br/arquivos_down/seges/Legislacao_sobre_estruturas_06032006.pdf $>$. Acesso em: set. 2007.

. Lei ํㅡ 5.645, de 10 de dezembro de 1970. Estabelece diretrizes para a classificação de cargos do serviço civil da União e das autarquias federais, e dá outras providências. Disponível em: <www.planalto.gov.br/ccivil_03/Leis/Lei_principal. htm>. Acesso em: set. 2007.

. Lei no 8.112, de dezembro de 1990. Dispõe sobre regime jurídico dos servidores públicos civis da União, das autarquias e das fundações públicas federais. Disponível em: <www.planalto.gov.br/ccivil_03/Leis/Lei_principal.htm>. Acesso em: set. 2007. 
. Decreto $\mathrm{n}^{\circ}$ 77.336, de 25 de março de 1976. Reestrutura o grupo-direção e assessoramentos superiores, de que trata a Lei oㅡ 5.645, de 10 de dezembro de 1970, e dá outras providências Disponível em: <www.planalto.gov.br/ccivil_03/ Leis/Lei_principal.htm>. Acesso em: set. 2007.

BRONZO, Marcelo; GARCIA, Fernando Coutinho. As bases epistemológicas do pensamento administrativo convencional e a crítica à Teoria das Organizações. In: RODRIGUES, Suzana Braga; CUNHA, Miguel P. (Orgs.). Estudos organizacionais: novas perspectivas da administração de empresas. São Paulo: Iglu, 2000.

CALDAS, Miguel; FACHIN, Roberto. Paradigma funcionalista: desenvolvimento de teorias e institucionalismo nos anos 1980 e 1990. RAE, v. 45, n. 2, abr./jun. 2005.

; WOOD Jr., Thomaz. Para inglês ver: importação de tecnologia gerencial no Brasil. In: . (Orgs.). Transformação e realidade organizacional: uma perspectiva brasileira. São Paulo: Atlas, 1999.

CARDOSO, Fernando Henrique. Autoritarismo e democratização. Rio de Janeiro: Paz e Terra, 1975.

CARVALHO, Cristina Amélia; LOPES, Fernando Dias. Convergência estrutural e processual entre teatros e museus no Rio Grande do Sul. In: ENCONTRO ANUAL DA ASSOCIAÇÃO NACIONAL DOS PROGRAMAS DE PÓS-GRADUAÇÃO EM ADMINISTRAÇÃO, 25., Campinas. Anais... Campinas: Anpad, 2001.

CARVALHO, José Murillo de. A construção da ordem: a elite política imperial. Rio de Janeiro: Campus, 1980. 1988.

. Teatro de sombras: a política imperial. Rio de Janeiro: Vértice/Iuperj,

(Org.). Entre a autoridade e a liberdade. Introdução à obra de Visconde do Uruguai "Ensaio sobre direito administrativo", de 1861. São Paulo: 34, 2002. Coleção Formadores do Brasil.

CATANI, Alfredo Mendes; CATANI, Denise Bárbara; PEREIRA, Gilson. As apropriações da obra de Pierre Bourdieu no campo educacional brasileiro através de periódicos da área. Revista Brasileira de Educação, n. 17, maio/ago. 2001.

CORCUFF, Philippe. As novas sociologias: construções da realidade social. Bauru, SP: Edusp, 2001.

D’ARAUJO, Maria Celina (Org.). Governo Lula: contornos sociais e políticos da elite do poder. Rio de Janeiro: Cpdoc/FGV, 2007.

DIMAGGIO, Paul J.; POWELL, Walter W. (Eds.). The new institutionalism in organizational analysis. Chicago: University of Chicago Press, 1991. 
DI PIETRO, Maria Sylvia Zanella. Direito administrativo. São Paulo: Atlas, 1999.

DRAIBE, Sônia Miriam. Rumos e metamorfoses: um estudo sobre a constituição do estado e as alternativas da industrialização no Brasil, 1930-1960. 2. ed. Rio de Janeiro: Paz e Terra, 2004.

FARIA, Carlos Aurélio Pimenta de. Ideias, conhecimento e políticas públicas: um inventário sucinto das principais vertentes analíticas recentes. Revista Brasileira de Ciências Sociais, v. 18, n. 51, p. 21-30, fev. 2003.

FAYOL, Henry. The administrative theory in the state. In: GULICK, Luther Halsey; URWICK, Lyndall Fownes. Papers on the science of administration. Clifton: Augusto M. Kelley Use 39268, 1973.

FISCHER, Tânia. Administração pública como área de conhecimento e ensino: a trajetória brasileira. Revista de Administração de Empresas, Rio de Janeiro, p. 278288, out./dez. 1984.

Alice através do espelho ou Macunaíma em campus papagali? Mapeando rotas de ensino dos estudos organizacionais no Brasil. O\&S, v. 10, n. 28, 2003 .

. Depoimentos sobre as trajetórias da qualificação para a administração pública no Brasil e itinerários baianos. In: Gestão pública: a trajetória da função administração no Estado da Bahia. Cadernos da Fundação Luís Eduardo Magalhães. Salvador: Flem, 2003b.

GABARDO, Emerson. Eficiência e legitimidade do Estado: uma análise das estruturas simbólicas do direito político. Barueri, SP: Manole, 2003.

GAETANI, Francisco. O ensino de administração pública no Brasil em um momento de inflexão. Revista do Setor Público, n. 4, Rio de Janeiro, out./dez. 1999.

GONZÁLEZ, José Juan Sánchez. La administración pública como ciencia: su objeto y su estudio. México: Plaza y Valdés, 2001.

GOUVEA, Gilda Figueiredo Portugal. Burocracia e elites burocráticas no Brasil. São Paulo: Paulicéia, 1994.

GRAHAM, Lawrence S. Civil service reform in Brazil: principles versus practice. Austin: Univ. Texas, 1977.

GULICK, L. H. Notes on the theory of organization. In: GULICK, Luther Halsey; URWICK, Lyndall Fownes. Papers on the science of administration. Clifton: Augusto M. Kelley Use 39268, 1973.

HEMAIS, B.; VERGARA, S. C. A cultura anglo-americana na produção brasileira: um estudo de intertextualidade de trabalhos em estudos organizacionais. In: ENANPAD, 24. Anais... Florianópolis, 2000. 
O jeito brasileiro de publicar em estudos organizacionais. Revista

Organização \& Sociedade, Salvador, Universidade Federal da Bahia, v. 8, n. 20, jan./abr. 2001.

KOONTZ, Harold; O'DONNELL, Cyril. Princípios de administração. 7. ed. São Paulo: Pioneira, 1973.

LAFER, Celso. JK e o plano de metas (1956-1961): processo de planejamento e sistema político no Brasil. Rio de Janeiro: FGV, 2002.

LASH, Scott. A reflexividade e seus duplos: estrutura, estética, comunidade. In: GIDDENS, Anthony; BECK, Ulrich; LASH, Scott. Modernização reflexiva: política, tradição e estética na ordem social moderna. São Paulo: Unesp, 1997.

LEÃO, Fernando Pontual de Souza J. Formação e estruturação de campos organizacionais: um modelo para a análise do campo cultural. In: ENCONTRO ANUAL DA ASSOCIAÇÃO NACIONAL DOS PROGRAMAS DE PÓS-GRADUAÇÃO EM ADMINISTRAÇÃO, 25., Campinas. Anais... Campinas: Anpad, 2001.

LEFORT, Claude. Éléments d'une critique de la bureaucratie. Paris: UGE, 1983.

LESSA, Renato. A invenção republicana: Campos Sales, as bases e a decadência da Primeira República brasileira. 2. ed. São Paulo: Vértice, 1999.

MARCH, James; SIMON, Hebert. Teoria das organizações. 4. ed. Rio de Janeiro: FGV, 1979.

MARTINS, Luciano. Estado capitalista e burocracia no Brasil pós-64. 2. ed. Rio de Janeiro: Paz e Terra, 1991.

MATTOS, Ilmar R. O lavrador e o construtor: o Visconde do Uruguai e a construção da política imperial. In: PRADO, Maria Emília (Org.). O Estado como vocação. Rio de Janeiro: Access, 1999. p. 191-218.

. O tempo saquarema: a formação do Estado Imperial. 5. ed. São Paulo: Hucitec/INL, 2004.

MEDAUAR, Odete. Direito administrativo moderno. 6. ed. São Paulo: Revista dos Tribunais, 2002.

MELLO, Celso Antonio Bandeira de. Curso de direito administrativo. 14. ed. São Paulo: Malheiros, 2002.

MICELI, Sérgio. A força do sentido. In: BOURDIEU, Pierre. A economia das trocas simbólicas. 5. ed. São Paulo: Perspectiva, 1998.

MISOCZKY, Maria Ceci. Implicações do uso das formulações sobre campo de poder e ação de Bourdieu nos estudos organizacionais. Revista de Administração Contemporânea, v. 7, 2003. Edição Especial. 
. Uma defesa da reflexão teórico-crítica na pesquisa e prática da administração pública. In: ENCONTRO NACIONAL DE ADMINISTRAÇÃO PÚBLICA E GOVERNANÇA — EnAPG. Anais... Rio de Janeiro, 2004.

MODESTO, Paulo. Função administrativa. RSP, Brasília, v. 119, n. 2-3, maio/dez. 1995.

MOTTA, Fernando C. Prestes; ALCADIPANI, Rafael; BRESLER, Ricardo B. A valorização do estrangeiro como segregação nas organizações. Revista de Administração Contemporânea, p. 59-79, 2001. Edição Especial.

NUNES, Edson. A gramática política do Brasil: clientelismo e insulamento burocrático. Rio de Janeiro: Zahar, 1997.

OSZLAK, Oscar. Políticas públicas e regimes políticos: reflexões a partir de algumas experiências latino-americanas. RAP, Rio de Janeiro, 1975.

. Notas críticas para una teoría de la burocracia estatal. Buenos Aires: Doc. Cedes/G. E. Clacso n. 8, 1977.

PECI, Alketa. Estrutura e ação nas organizações. Revista de Administração de Empresas, v. 43, n. 1, jan./fev./mar. 2003.

PETERS, Gabriel Moura. Percursos na Teoria das Práticas Sociais: Anthony Giddens e Pierre Bourdieu. 2006. Dissertação (Mestrado) — Departamento de Sociologia, Universidade de Brasília, Brasília.

PINTO, Elida Graziane. Por uma administração pública (gerencial ou não) mais accountable no Brasil: entre outras coisas, uma questão de respeito às salvaguardas constitucionais. In: Documentos debate: Estado, Administración Pública y Sociedad. Concurso de Ensayos y Monografías sobre Reforma del Estado y Modernización de la Administración Pública, 15. Control y evaluación del desempeño gubernamental. Ensayos Ganadores 2001. Menciones Honoríficas. Caracas: Clad, n. 7, abril 2002.

PINTO, Louis. Pierre Bourdieu e a teoria do mundo social. Rio de Janeiro: FGV, 2000 .

PRATS I CATALÁ, Joan. Direito e gerenciamento nas administrações públicas. Revista do Serviço Público, ano 47, v. 120, n. 2, maio/ago. 1996.

REED, Michael. Teorização organizacional: um campo historicamente contestado. In: CLEGG, Stewart; HARDY, Cynthia; NORD, Walter. CALDAS, Miguel; FACHIN, Roberto; FISCHER, Tânia (Orgs.). Handbook de estudos organizacionais. São Paulo: Atlas, 1999. cap. 1, p. 61-98.

RISCAL, Sandra. O conceito de soberania em Jean Bodin: um estudo do desenvolvimento das ideias da administração pública, governo e Estado no século XVI. 
2001. Tese (Doutorado) — Faculdade de Educação, Universidade Estadual de Campinas, Campinas, SP.

RODRIGUES, Suzana Braga; CARRIERI, Alexandre de Pádua. A tradição anglosaxônica nos Estudos Organizacionais. In: ENEO - ENCONTRO DE ESTUDOS ORGANIZACIONAIS, 1. Anais eletrônicos... Curitiba, 2000.

ROSENBLOOM, David H. Editorial: Have an administrative Rx? Don't forget the pol. Public Administration Review, ABI/Inform Global; v. 53, n. 6; p. 503, Nov./Dec. 1993.

SCHNEIDER, Ben Ross. Burocracia pública e política industrial no Brasil. São Paulo: Sumaré, 1994.

SCHWARTZ, Stuart B. Burocracia e sociedade no Brasil colonial: a suprema corte da Bahia e seus juízes, 1609-1751. São Paulo: Perspectiva, 1979.

SIRAQUE, Vanderlei. O controle social da função administrativa do Estado: possibilidades e limites na Constituição de 1988. 2004. Dissertação (Mestrado em Direito) — PUC-SP, São Paulo.

SOUZA, Maria do Carmo Campello de. Federalismo no Brasil: aspectos políticoinstitucionais (1930-1964). Revista Brasileira de Ciências Sociais, v. 21, n. 61, p. 7-40, jun. 2006.

SPINK, Peter. Possibilidades técnicas e imperativos políticos em 70 anos de reforma administrativa. In: BRESSER-PEREIRA, Luiz Carlos; SPINK, PETER (Orgs.). Reforma do Estado e administração pública gerencial. Rio de Janeiro: FGV, 1998.

SUNFELD, Carlos Ari. Fundamentos do direito público. 4. ed. São Paulo: Malheiros, 2006.

TAYLOR, Frederick Winslow. Principios de administração científica. 5. ed. São Paulo: Atlas, 1963.

THIRY-CHERQUES, Hermano Roberto. Pierre Bourdieu: a teoria na prática. RAP, Rio de Janeiro, v. 40, n. 1, p. 27-55, jan./fev. 2006.

THOENIG, Jean-Claude. Recuperando a ênfase na dimensão pública dos estudos organizacionais. RAP, Rio de Janeiro, v. 41, set. 2007. Disponível em: <www.scielo. br/scielo.php?script $=$ sci_arttext\&pid $=$ S0034-76122007000700002\&lng $=$ pt $\&$ nrm =iso $>$. Acesso em: dez. 2007.

TURNER, Jonathan H. Teorização analítica. In: GIDDENS, Anthony; TURNER, Jonathan. Teoria social hoje. São Paulo: Unesp, 1999. p. 229-280.

URUGUAI, Visconde do. Ensaio sobre direito administrativo. 1861. São Paulo: 34, 2002. Coleção Formadores do Brasil. 
VERGARA, Sylvia C. A hegemonia americana em estudos organizacionais. Revista de Administração Pública, v. 35, n. 2, 2001.

; CARVALHO JR., D. Nacionalidade dos autores referenciados na literatura brasileira sobre organizações. RAC, Rio de Janeiro, Anpad, v. 1, 1995.

; CARVALHO JR., D. Refletindo sobre as possíveis consequências de análise organizacional apoiada em referências estrangeiras. Revista Brasileira de Administração Pública, v. 30, n. 6, 1996.

; PINTO, M. C. S. Referências teóricas em análise organizacional: um estudo das nacionalidades dos autores referenciados na literatura brasileira. Revista de Administração Contemporânea, Edição Especial, 2001.

VIEIRA DA CUNHA, Mario W. O sistema administrativo brasileiro (1930-1950). Rio de Janeiro: Ministério da Educação e Cultura, 1963.

WACQUANT, Loïc. O poder simbólico na dominação da 'nobreza de Estado'. In: . (Org). O mistério do ministério: Pierre Bourdieu e a política democrática. Rio de Janeiro: Revan, 2005.

WAHRLICH, Beatriz M. S. Reforma administrativa na era de Vargas. Rio de Janeiro: FGV, 1983.

. Evolução das ciências administrativas na América Latina. RAP, v. 13, n. 1, p. 31-68, 1979.

WALDO, Dwight. O estudo da administração pública. 2. ed. Rio de Janeiro: FGV, 1971.

WEBER, Max. Sociologia. São Paulo: Ática, 1979.

$\overline{1993 .}$

. Parlamentarismo e governo na Alemanha reordenada. Rio de Janeiro: Vozes,

_. Economia e sociedade. 3. ed. Brasília: Universidade de Brasília, 2000a. v. $1-2$.

. Ciência e política: duas vocações. 10. ed. São Paulo: Cultrix, 2000 b.

. Metodologia das ciências sociais. 3. ed. São Paulo: Cortez, 2001.

WILLOUGHBY, W. F. The government of modern states. New York: Appleton Century Crofts, 1919.

Press, 1929.

. Principles of public administration. Baltimore/MD: The Lord Baltimore

WILSON, Woodrow. Estudo da administração (1887). In: WALDO, Dwight. Problemas e aspectos da administração pública. São Paulo: Pioneira, 1966. 